\title{
A case of granuloma faciale successfully treated with oral prednisone, tranilast and thalidomide
}

\author{
Chunyu Yuan, Wenbo Bu, Xu Chen, Heng Gu
}

Institute of Dermatology, Jiangsu Key Laboratory of Molecular Biology for Skin Diseases and STIs, Chinese Academy of Medical Science and Peking Union Medical College, Nanjing, China

Adv Dermatol Allergol 2018; XXXV (1): 109-112

DOI: https://doi.org/10.5114/ada.2018.73170

Granuloma faciale (GF) is an uncommon benign vascular inflammatory dermatosis with unclear etiology, usually occurring in middle-aged Caucasian men [1]. Clinically, the lesions of GF are characterized by single or multiple violaceous or reddish-brownish plaques, papules or nodules. Lesions are usually asymptomatic and grow slowly [2]. The typical histopathology of GF consists of mixed nodular inflammatory infiltration mainly composed of eosinophils and neutrophils in the dermis, and the "Grenz zone" in the superior dermis. In fresh lesions, there is observed leukocytoclastic vasculitis, and the old lesions show fibrosis and vascular proliferation [1]. Granuloma faciale is resistant to many treatments and prone to relapse. The typical therapies include topical, intralesional or systemic corticosteroid [3], dermabrasion [4], cryotherapy [5], laser treatments [6], and psoralen with ultraviolet A [7]. Other systemic treatments involve dapsone [3, 8], hydroxychloroquine [9] and clofazimine [10]. Here, we report a case of GF successfully treated with combined treatment of topical and systemic corticosteroids, tranilast and thalidomide.

A 58-year-old male patient was admitted to our hospital in June, 2015 with a 5- to 6-year history of facial and cheek itchy red plaques. Initially, the rash presented as ring-like erythema, gradually enlarging to form prominent nodular plaques with severe itching. This patient had no history of systemic disease or family history of genetic disease. There was no fever or trauma history before the onset and progression of the disease.

Systemic physical examination was normal. Skin lesions manifested dark-red plaques in irregular shapes scattering at the glabella and left cheek with a prominent edge. The middle area of partial lesions formed crusts and scaling. There was no skin atrophy or tenderness and the plaque was soft upon palpation (Figure 1).

There was no abnormality in the routine blood examination and the fungi microscopic detection. Histopa- thology features presented (Figure 2) hyperkeratosis with focal parakeratosis, hyperacanthosis and acanthosis with edema, liquefactive degeneration in some parts of the basal layer, mild edema in the superficial dermis, dilation and hyperemia of blood vessels, diffused infiltration of eosinophils, neutrophils, lymphocytes and histiocytes in the dermis and subcutaneous fat tissue, accompanied by hyperplasia of collagen. Infiltration of inflammatory cells was not involved in the upper part of the dermal papilla, and formed a clear non-infiltration zone (Grenz zone). The histology presented a typical feature of granuloma faciale.

For treatment, oral prednisone $(20 \mathrm{mg}$ ) was administered once per day at $8 \mathrm{am}$. No new rash occurred and the color of original skin lesions faded after 1 month of treatment. The dosage of prednisone was reduced to $10 \mathrm{mg}$ once per day at $8 \mathrm{am}$. Two weeks later, the amount of oral prednisone was reduced to alternative administration of $5 \mathrm{mg}$ and $10 \mathrm{mg}$ for 10 days, then reduced to $5 \mathrm{mg}$ at 8 am each per day for 9 days until drug withdrawal; oral thalidomide was administered $25 \mathrm{mg} /$ dose three times a day for 20 days from the beginning of prednisone application, and reduced to twice daily at $25 \mathrm{mg} /$ dose for 1 month; oral tranilast was given at $0.1 \mathrm{~g} /$ dose, twice daily for 24 days. Topical mometasone furoate ointment was applied at the skin lesions twice daily. The lesions were completely controlled after 63 days of treatment (Figure 1) and no recurrence occurred in 6 months follow-up.

Granuloma faciale is a disease of chronic eosinophil infiltrated leukocytoclastic vasculitis, its pathogenesis is unclear, and it may involve the activation and proliferation of $T$ lymphocytes and increased synthesis of proinflammatory factors such as tumor necrosis factor- $\alpha$ (TNF- $\alpha$ ), interferon- $\gamma$ (IFN- $\gamma$ ), IL-5, and IL-2 $[1,11]$. Glucocorticoid has the effect of immunosuppression, antiinflammation, inducing apoptosis of inflammatory cells

Address for correspondence: Xu Chen, Heng Gu, Institute of Dermatology, Jiangsu Key Laboratory of Molecular Biology for Skin Diseases and STIs, Chinese Academy of Medical Science and Peking Union Medical College, 12 Jiangwangmiao St, 210042 Nanjing, China, phone: +86 258547 8919, fax: +86 25 85414477, e-mail: doctor_chx@hotmail.com, doctor_guheng@hotmail.com Received: 10.10.2016, accepted: 3.01.2017. 

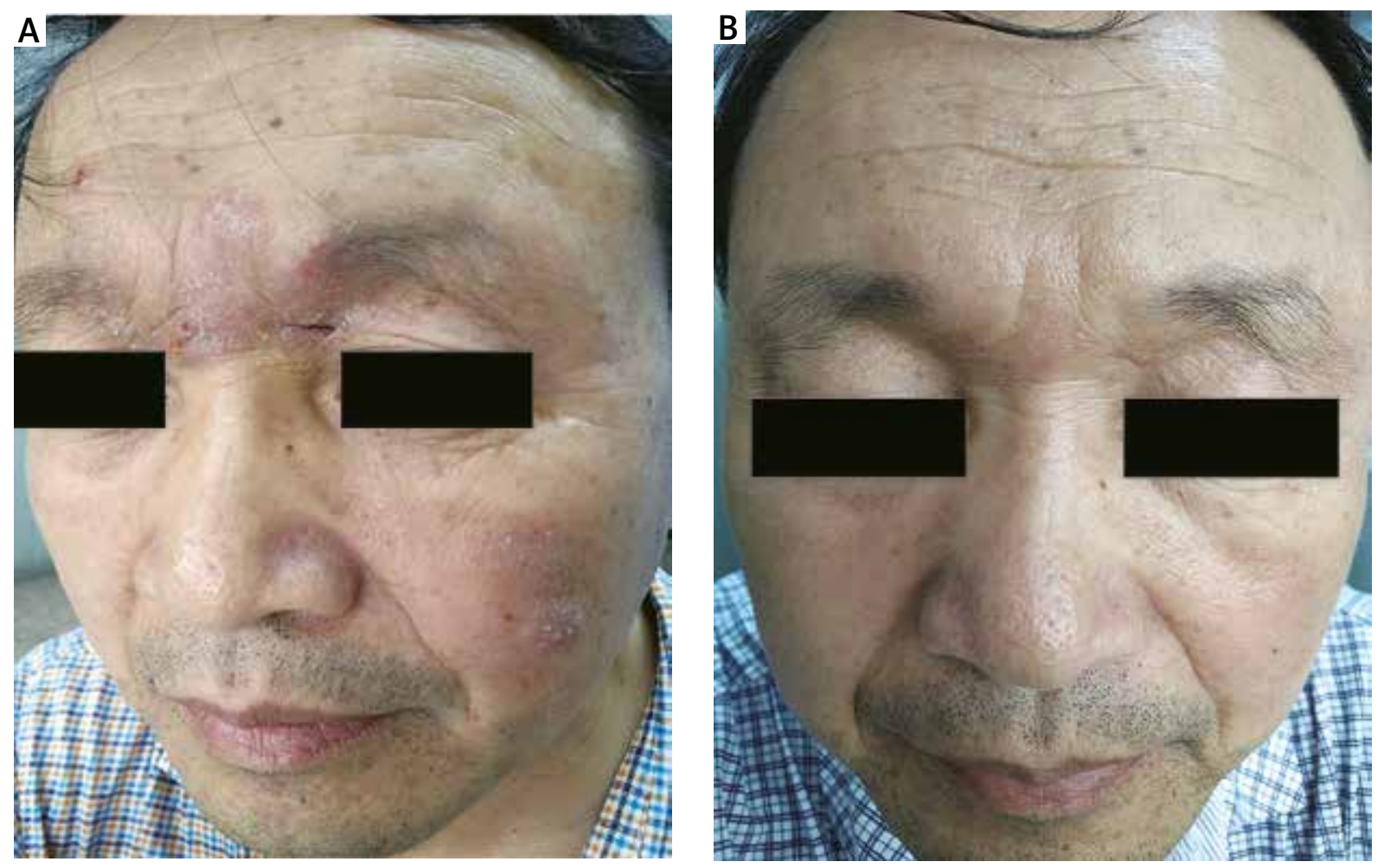

Figure 1. A - Clinical features before treatment. B - Disappearance of skin lesion after treatment

and cytostatic action [3]. Thalidomide shows strong immunomodulatory and anti-inflammatory effects and it can inhibit chemotaxis of leukocytes, the proliferation of lymphocytes and the production of inflammatory factors (TNF- $\alpha$, IFN- $\gamma$ ), reduce the production of hydroxyl and superoxide radicals in the inflammation sites, and resist angiogenesis [12]. The remission of the patient's condition was associated with the anti-inflammatory effect of combination application of the two above-mentioned drugs. Tranilast is the analogue of tryptophan metabolites. It acts as an anti-fibrosis agent so is suitable in the treatment of keloid, scleroderma and other fibrotic diseases. It inhibits profibrotic growth factors, including transforming growth factor- $\beta$ (TGF- $\beta$ ), platelet-derived growth factor (PDGF) and connective tissue growth factor (CTGF). Tranilast also inhibits angiogenesis [13]. Fibrosis and vascular proliferation can be observed at the remote skin lesions of GF. In this case, the histopathology indicated collagen hyperplasia; therefore tranilast is effective in this patient.

Although multiple therapies were reported, the treatment of GF is difficult [2]. For example, Teixeira et al. [8] reported that a GF patient was treated with betamethasone dipropionate $0.05 \%$ cream and prednisone $60 \mathrm{mg} /$ day for 2 months, and the lesions did not improve. Then, they chose intralesional corticosteroid and dapsone $100 \mathrm{mg} /$ day for 9 months with lesions' partial improvement. Gupta et al. [14] reported that a female with a 5-year history of lesions on the left cheek was given dapsone $100 \mathrm{mg}$ twice daily for about 1 year with no improvement. Subsequently, medical treatment was stopped and six sessions of cryotherapy were started until erythema and itching emerged. Finally, topical tacrolimus $0.1 \%$ ointment twice daily was applied for 3 months with improvement of $40-50 \%$ of lesions. In addition, Paradisi et al. [6] reported treatment with carbon dioxide gas laser for drug-resistant GF. Although destructive treatments such as surgery or laser for GF were effective, the scarring and rapid recurrence need to be considered [5]. In this case, the skin lesions were successfully cured by the oral application of corticosteroid, tranilast and thalidomide with combination of topical corticosteroid ointment after 63 days of treatment. However, a longterm follow-up is needed to validate the efficacy of this therapy. Oral corticosteroid is a traditional method for treatment of GF [15], but long-term application often leads to various side effects. This case suggests that the use of thalidomide and tranilast can enhance the efficacy of corticosteroid and decrease the daily and total dosage of corticosteroid, therefore preventing the adverse effects of corticosteroid.

\section{Acknowledgments}

Chunyu Yuan and Wenbo Bu equally contributed to this article. 


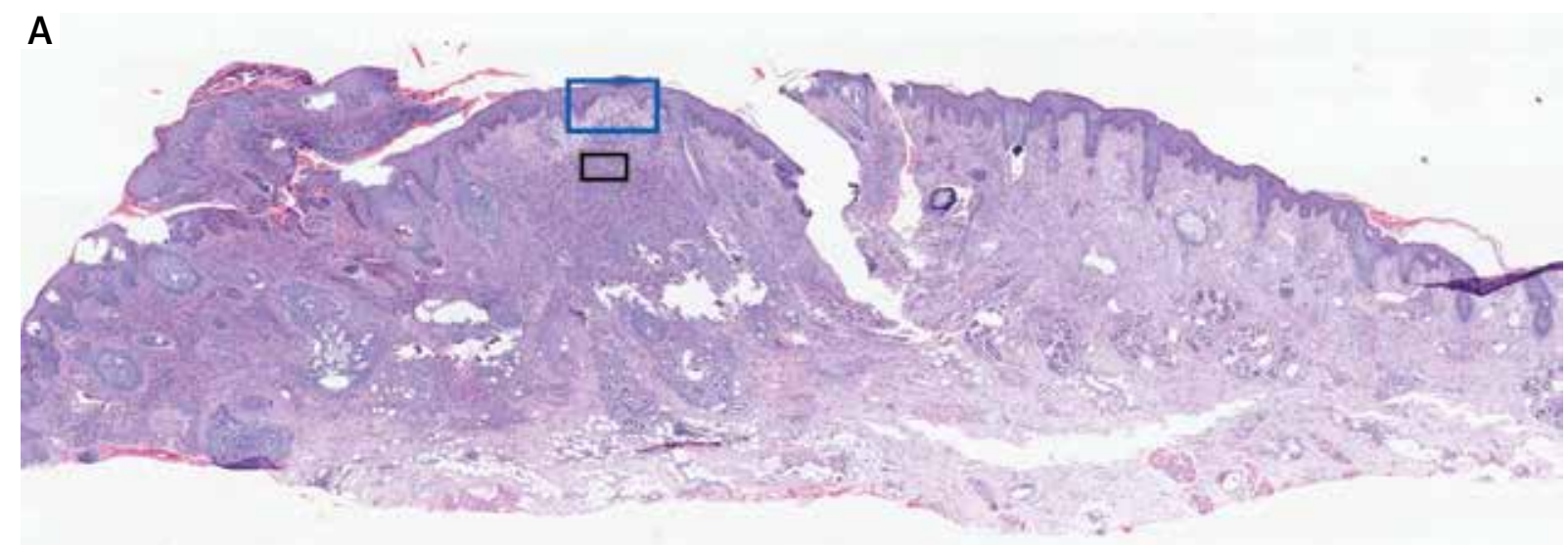

\section{$4 \mathrm{~mm}$}
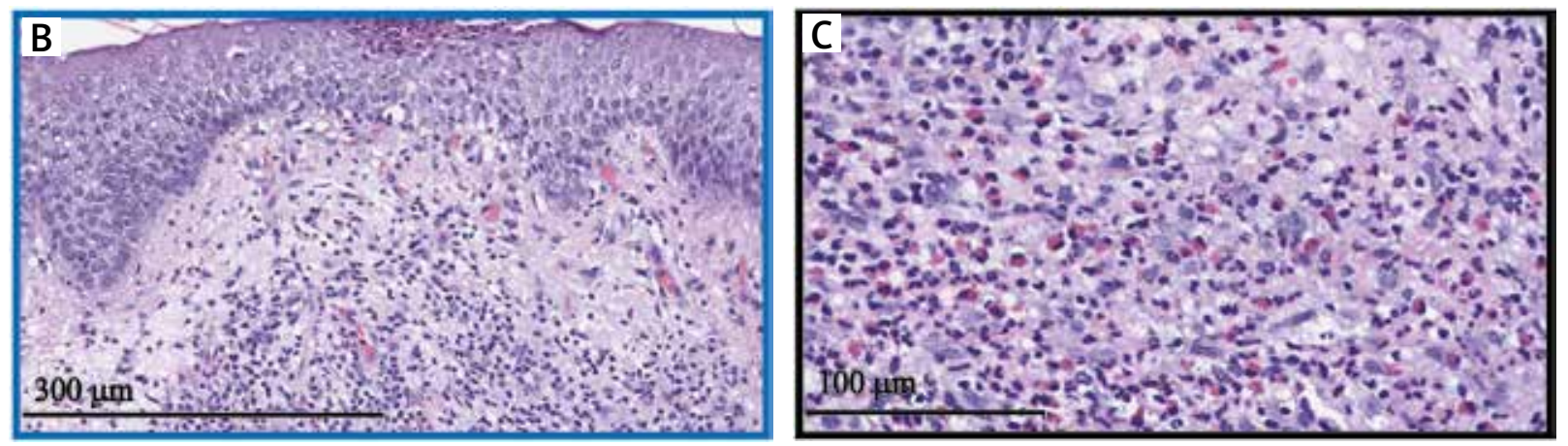

Figure 2. A - Histopathologic observation at low magnification view shows perivascular nodular infiltration with inflammatory cells within the dermis and a 'Grenz' zone. B - Observation in the blue frame located at (A) showed the 'Grenz' zone, inflammatory infiltrate in dermis and fibrinoid deposits within vessel walls. $\mathbf{C}-$ Observation in the black frame located at $(A)$ showed the dense and diffused inflammatory infiltrate in dermis mainly composed of eosinophils, neutrophils, lymphocytes and histiocytes. Scale bars are indicated in (A), (B) and (C)

This work was supported by grants from the National Natural Science Foundation of China (No. 81371755), the PhD Programs Foundation of the Ministry of Education of China (No. 20131106120046), the Jiangsu Provincial Special Program of Medical Science (BL2012003), the Jiangsu Province Natural Science Foundation (No. BK20150068) and PUMC Youth Fund and Fundamental Research Funds for the Central Universities (3332015116, 3332014008, 2016RC320005, 2016ZX320014).

\section{Conflict of interest}

The authors declare no conflict of interest.

\section{References}

1. Ortonne N, Wechsler J, Bagot M, et al. Granuloma faciale: a clinicopathologic study of 66 patients. J Am Acad Dermatol 2005; 53: 1002-9.
2. Michajłowski I, Sobjanek M, Kozicka D, et al. Granuloma faciale - analysis of 5 cases. Postep Dermatol Alergol 2011; 28: 36-40.

3. Ludwig E, Allam JP, Bieber T, et al. New treatment modalities for granuloma faciale. Br J Dermatol 2003; 149: 634-7.

4. Dinehart SM, Gross DJ, Davis CM, et al. Granuloma faciale. Comparison of different treatment modalities. Arch Otolaryngol Head Neck Surg 1990; 116: 849-51.

5. Maillard H, Grognard C, Toledano C, et al. Granuloma faciale: efficacy of cryosurgery in 2 cases. Ann Dermatol Venereol 2000; 127: 77-9.

6. Paradisi A, Ricci F, Sbano P. "Drug-resistant granuloma faciale": treatment with carbon dioxide-GaAs laser. Dermatol Ther 2016; 29: 317-9.

7. Hudson LD. Granuloma faciale: treatment with topical psoralen and UVA. J Am Acad Dermatol 1983; 8: 559.

8. Teixeira DA, Estrozi B, Ianhez M. Granuloma faciale: a rare disease from a dermoscopy perspective. An Bras Dermatol 2013; 88: 97-100.

9. Rossiello L, Palla M, Aiello FS, et al. Granuloma faciale with extrafacial lesions. Skinmed 2007; 6: 150-1. 
10. Jacyk WK. Facial granuloma in a patient treated with clofazimine. Arch Dermatol 1981; 117: 597-8.

11. Tojo G, Fujimura T, Kambayashi Y, et al. Successful treatment of granuloma faciale with topical tacrolimus: a case report and immunohistochemical study. Case Rep Dermatol 2012; 4: 158-62.

12. Wu JJ, Huang DB, Pang KR, et al. Thalidomide: dermatological indications, mechanisms of action and side-effects. $\mathrm{Br}$ J Dermatol 2005; 153: 254-73.

13. Darakhshan S, Pour AB. Tranilast: a review of its therapeutic applications. Pharmacol Res 2015; 91: 15-28.

14. Gupta L, Naik H, Kumar NM, et al. Granuloma faciale with extrafacial involvement and response to tacrolimus. J Cutan Aesthet Surg 2012; 5: 150-2.

15. Barham KL, Jorizzo JL, Grattan B, Cox NH. Granuloma faciale. In: Rook's Textbook of Dermatology. Tony B, Stephen B, Neil C, Christopher G (eds). Blackwell Science. UK, 2004; 3: 49.16-7. 